\title{
Optimization of a Microwave Assisted Extraction of Organic Sulphur from Domestic Sewage Sludge by UV-Vis Spectrophotometry Determination
}

\author{
Darlan Ferreira Silva (Corresponding author) \\ Chemistry Institute of São Carlos \\ University of São Paulo, Avenida Trabalhador São Carlense, \\ São Carlos-SP 13566 590, Brazil \\ E-mail: darlanveggito@hotmail.com \\ Maria Olimpia Oliveira Rezende \\ Department of Chemistry, Chemistry Institute of São Carlos \\ University of São Paulo, Avenida Trabalhador São Carlense, \\ São Carlos-SP 13566 590, Brazil
}

Received: September 20, 2017 Accepted: October 4, 2017 Published: October 10, 2017

doi:10.5296/jas.v5i4.11888

URL: https://doi.org/10.5296/jas.v5i4.11888

\begin{abstract}
An alternative method for microwave-assisted extraction of organic sulphur in sewage sludge samples was optimized based on response surface methodology. The extraction process was defined by a $2^{3}$ factorial design. In the factorial design, the temperature, the extraction time and the volume of hydrochloric acid in the solvent mixture were evaluated. The samples were extracted with a mixture of nitric acid and hydrochloric acid. The data obtained for study were based on the concentration of sulphur in the sulfate form $\left(\mathrm{S}_{-} \mathrm{SO}_{4}{ }^{2-}\right)$ obtained spectrophotometrically in the sludge samples. The initial extraction parameters were adjusted so that spectrophotometric determination was feasible. According to the levels (minimum and maximum) defined for each parameter, the methodology showed that the best extraction conditions were achieved with an extraction temperature of $150{ }^{\circ} \mathrm{C}$, using a longer extraction time (40 min). This study was carried out to evaluate the efficiency of microwave-assisted extraction in spectrophotometric determination of sulphur in sludge samples.
\end{abstract}


Keywords: Microwave-Assisted Extraction, Factorial Design, Organic Sulphur, Sewage Sludge, Soil.

\section{Introduction}

Sewage sludge is one of the residues obtained in the treatment of water, with the purpose of making it suitable for the disposal of receiving water bodies, with the least possible environmental impact. One of the alternatives for the use of the sludge in the final disposal is its use in agriculture, as it can allow improvements in soil quality and economic return due to reduced use of mineral fertilizers (Gomes et al, 2007).

Sludge, nowadays called biosolid, is a product of organic origin that results from the treatment of sewage effluents and can be recycled, as long as it does not cause environmental damage, to human or another animal health. Agriculture and industry can benefit from silt production for agricultural purposes, as well as using the soil as a conditioner to recover degraded areas (Heck et al, 2012).

In soil, sulfur is present in inorganic and organic form. Inorganic sulphur is a readily available fraction for the roots of plants, representing less than $5 \%$ of the total sulphur in the soil. Another $95 \%$ are in soil in the form of organic molecules and are exclusively available to plants (Lucheta \& Lambais, 2012).

Sulphur plays an essential role in plants, being one of the main nutrients in several metabolic processes. Conventional methods for the oxidation of organic sulphur to sulfate use nitric acid and perchloric acid, which requires safety measures against fire and explosion, in addition to the possibility of material loss, which may render the method useless (ROSSETE et al, 2012).

For measurements of total sulphur in soil sample and sediment, various forms of sulphur are converted to sulfates by oxidation. This conversion process is difficult and requires special techniques. The techniques used to determine total sulphur in solid samples include acid oxidation methods, which are time consuming, susceptible to contamination and cause risk of explosion, fire and material loss. The acid digestion is carried out in the presence of nitric and hydrochloric acid heated in a digester block at temperatures of 190 to $210{ }^{\circ} \mathrm{C}$. This type of digestion requires caution (Rossete et al, 2011; Khan, Shang and Alam, 2012).

Microwave-assisted extraction (MAE) is a process that uses the energies of the microwave to effectively heat the solvent so that the analytes can be easily separated from the matrix into the solvent. As can also significantly reduce extraction time and solvent consumption (Li et al, 2012; Silva, Azevedo and Rezende, 2016).

Compared with conventional heating methods, MAE is environmentally friendly and is now well established, reducing energy consumption and reaction time. In addition, microwave heating does not have direct contact with the heated material, because the radiation works on the solvent molecule. Microwave extraction has been widely used in several applications such as synthesis, sample digestion, extraction, pretreatment of samples and stabilization of metal ions (Huang et al, 2015). 
Turbidimetry is an analytical method that can be performed in a molecular spectrophotometer, and unlike the theoretical concept of the use of this equipment that is based on molecular absorption, turbidimetry is based on the spread of radiation by suspended particles. The turbidimetric analysis is widely used in the determination of sulfates in several types of matrices, such as plants (Rossete et al, 2011), soil (Rossete et al, 2008) and fertilizers (Vicente et al., 2001).

The method of sulphur determination developed by Tabatabai (1974) is based on the measurement of the turbidity formed by the reaction of the barium chloride with the sulphate present in the sample, forming barium sulfate, according to reaction:

$$
\mathrm{Ba}^{2+}+\mathrm{SO}_{4}{ }^{2-} \rightarrow \mathrm{BaSO}_{4}
$$

The principle of the method is based on the reaction of sulphates presented in the sample, after extraction with barium chloride, and in the insolubility of barium sulphate in dilute hydrochloric acid solution. A problem in the determination by the turbidimetric method is the color of the final extract, which must be clear, so as to avoid reading errors in the spectrophotometer.

The sulfate ion is precipitated in acid solution with barium chloride. The light absorbance of the barium sulfate suspension is measured spectrophotometrically and the sulphur concentration in the sulfate form $\left(\mathrm{S}_{-} \mathrm{SO}_{4}{ }^{2-}\right)$ is determined by comparing the obtained data with the analytical curve.

This work aimed to optimize an extraction methodology for the determination of organic sulphur $\left(\mathrm{S}_{-} \mathrm{SO}_{4}{ }^{2-}\right)$ in sewage sludge samples by UV-Vis spectrophotometry.

\section{Experimental}

\subsection{Samples}

The sewage sludge samples were collected in the Wastewater Treatment Plant of São Carlos, Brazil, and cooled at $4{ }^{\circ} \mathrm{C}$ after the collection.

\subsection{Reagents}

Nitric acid and hydrochloric acid were purchased from PANREAC and TEDIA, respectively. Barium chloride and sodium sulfate, both were purchase from SYNTH. Hydrochloric acid solution of $6 \mathrm{~mol} \mathrm{~L}^{-1}$ was prepared by dissolving approximately $184 \mathrm{~mL}$ of $\mathrm{HCl}$ in approximately $500 \mathrm{~mL}$ of water, then transferring to a $1 \mathrm{~L}$ volumetric flask, filling the volume with distilled water.

The barium chloride solution (100 $\mathrm{g} \mathrm{L}^{-1}$ ) was prepared by dissolving $100 \mathrm{~g}$ of $\mathrm{BaCl}_{2}$ in approximately $500 \mathrm{~mL}$ of water and then transferring into a $1 \mathrm{~L}$ volumetric flask, filling the volume with distilled water.

\subsection{Stock Solution of Sodium Sulfate}

The solution containing sulfur was prepared by dissolving $2.21 \mathrm{~g}$ of $\mathrm{Na}_{2} \mathrm{SO}_{4}$ in approximately $50 \mathrm{~mL}$ of water. After dissolution, it was transferred into a $1000 \mathrm{~mL}$ volumetric flask and the volume was filling with distilled water. The solutions used in the analytical curve for 
turbidimetric determination were obtained by diluting the stock solution in order to obtain standard solutions of $10,25,50,75,100$ and $200 \mathrm{mg} \mathrm{L}^{-1}$. The turbidimetric measurements were performed in a UV-Vis (HACH) spectrophotometer, model DR6000.

\subsection{Microwave-assisted Extraction - MAE}

MAE was performed on a Speedwave Four ${ }^{\circledR}$ - microwave digestion system (Berghof, Germany) with built-in non-contact, temperature and pressure measurement, with a capacity of 12 vessels of $60 \mathrm{~mL}$ and $1450 \mathrm{~W}$ maximum power. The extraction vessels consist of vessels made entirely of TFM®. $0.5 \mathrm{~g}$ of sample was transferred into the extraction vessel and then $8 \mathrm{~mL}$ of mixture of nitric acid $(7 \mathrm{~mL})$ and hydrochloric acid $(1 \mathrm{~mL})$ was added into it. The vessels were shaken gently for 5 minutes before being closed. Once closed, the vessels were placed into the microwave extraction system. The magnetron power output of the microwave unit was set at $90 \%(1305 \mathrm{~W})$. The extraction temperature ranged from 150 to $170{ }^{\circ} \mathrm{C}$, the irradiation times tested were 15 and $40 \mathrm{~min}$. The ramp time $(8 \mathrm{~min})$ has been previously set, evaluating the time necessary for the system to reach the programmed maximum temperature $\left(170{ }^{\circ} \mathrm{C}\right)$. Then the system was turned on and temperature, time, ramp time and power were adjusted according the experimental design. After completion of the extraction the vessel with samples were cooled at room temperature for about 30 minutes. Finally, the extract was filtrated and transferred into a $100 \mathrm{~mL}$ flask, filling the volume with distilled water. Table 1 shows the operating conditions of extraction.

Table 1. MAE operational conditions.

Magnetron power

Ramp*

Extraction temperature

Extraction time

Solvent volume

Sample weight

Maximum vessel pressure
$90 \%(1305 \mathrm{~W})$

$8 \min$

$150-170^{\circ} \mathrm{C}$

$15-40 \mathrm{~min}$

$8 \mathrm{~mL}$

$0.5 \mathrm{~g}$ of dried sample

35 bar

*Time to reach settings

2.5 Preparation of the Standards and Samples: determination of $\mathrm{S}_{-} \mathrm{SO}_{4}{ }^{2-}$ (turbidimetric method)

The standard solutions were prepared in $50 \mathrm{~mL}$ Erlenmemyers using $10 \mathrm{~mL}$ of the stock solution, then adding $1 \mathrm{~mL}$ of $6 \mathrm{~mol} \mathrm{~L}^{-1}$ hydrochloric acid solution (to favor the nucleation process and improve the analytical sensitivity). After $30 \mathrm{~s}, 1 \mathrm{~mL}$ of $100 \mathrm{~g} \mathrm{~L}^{-1} \mathrm{BaCl}_{2}$ solution was added and allowed to stand for $1 \mathrm{~min}$. Then the mixture was stirred and transferred immediately to the cuvette of the spectrophotometer, carried out the measurements at $420 \mathrm{~nm}$. To prepare the samples, $10 \mathrm{~mL}$ aliquot was taken, $1 \mathrm{~mL}$ of $100 \mathrm{~g} \mathrm{~L}^{-1} \mathrm{BaCl}_{2}$ solution was 
added and allowed to stand for $1 \mathrm{~min}$ and then stirred and transferred to the cuvette of the spectrophotometer. During the assays for sulphur determination, care was taken to always maintain the same conditions in sample preparation, specifically the reaction time $(1 \mathrm{~min})$ after addition of $\mathrm{BaCl}_{2}$, the rate and time of agitation of sample.

\subsection{Experimental Design}

The extraction conditions were optimized based on the analysis of the response surfaces of evaluated parameters. In this study, the effects of three factors on the response (extraction yield) were evaluated through a $2^{3}$ factorial design, comprising 24 experiments in triplicate, performed randomly according to the experimental arrangement of the planning matrix.

Table 2 shows the factors and levels evaluated. All experimental data were defined according to preliminary experiments and the equipment programming conditions.

Table 2. Factors and their settings for $2^{3}$ experimental design for MAE.

\begin{tabular}{ccc}
\hline Factor & Minimum & Maximum \\
\hline Temperature $\left({ }^{\circ} \mathrm{C}\right)$ & 150 & 170 \\
Extraction time $(\mathrm{min})$ & 15 & 40 \\
$\mathrm{HCl}$ solution $(\%)$ & 12.5 & 25 \\
\hline
\end{tabular}

The investigated factors were: temperature $\left(\mathrm{X}_{1}, 150-170{ }^{\circ} \mathrm{C}\right)$, extraction time $\left(\mathrm{X}_{2}, 15-40 \mathrm{~min}\right)$ and hydrochloric acid percentage $\left(\mathrm{X}_{3}, 12.5-25 \%\right)$. A two-way interaction model was adjusted to the experimental data based on the equation 1 :

$$
\hat{y}=\beta_{0}+\beta_{1} x_{1}+\beta_{2} x_{2}+\beta_{3} x_{3}+\beta_{12} x_{1} x_{2}+\beta_{13} x_{1} x_{3}+\beta_{23} x_{2} x_{3}
$$

Where $\hat{y}$ is the predicted value (extraction yield), $\beta$ 's are the model coefficients and $x_{1}, x_{2}$, $\mathrm{x}_{3}$ the encoded factors. The Origin 8.0 software was used for analyzing the experimental data.

The range used to evaluate the independent variables were selected based on preliminary experiments, to obtain a clear extract so that the spectrophotometric determination was not impaired.

\section{Results and Discussion}

\subsection{Optimization of the Microwave-assisted Extraction - MAE}

Sewage sludge samples were digested using a mixture of $\mathrm{HCl}+\mathrm{HNO}_{3}$. Considering the significance of the temperature in the microwave extraction process, high temperature levels can cause an increase in the internal pressure of the extraction vessels, which may cause analyte losses and increase the risk of explosions (Silva, Landgraf and Rezende, 2015; Silva, Landgraf and Rezende, 2017). The use of microwaves in the extraction process generates energy, causing solvent heating and consequently in the sample that can suffer degradation or conversion of some compounds by different paths such as exposure to high temperatures and pressure within the extraction vessel (Barriada-Pereira et al., 2003). The optimization of a microwave extraction methodology should consider the interaction of the different factors involved in the extraction and the linear relationship between the responses and the variables (Du et al, 2010). 
Some adjustments were made in the initial factorial planning of the extraction methodology to assure the viability of the determinations by the turbidimetric method. Factors such as extraction temperature, total volume of acids in the vessels and the proportion of $\mathrm{HCl}$ solution in the acid mixture $\left(\mathrm{HNO}_{3}+\mathrm{HCl}\right)$ were previously evaluated so that the final extract obtained via MAE resulted in a transparent filtrate, appropriate for spectrophotometric determinations. According to the preliminary tests, when the set extraction temperature was higher than $180{ }^{\circ} \mathrm{C}$ and the sample volume used was $10 \mathrm{~mL}$, the safety system of the equipment was activated and the extraction procedure was not completed.

In order to avoid the risk of accidents with internal pressure of the vessels or with safety temperature of the equipment, the volume of solvent and extraction temperature were reduced. Tests with extraction temperature equal to $120^{\circ} \mathrm{C}$ and a volume of $6 \mathrm{~mL}$ of hydrochloric acid solution in the mixture, resulted in a yellowish filtrate, making the spectrophotometric determination impossible. With these observations, it was possible to define the experimental planning in order to reach the best extraction conditions. Table 3 shows the factorial design defined for the optimization of organic sulphur extraction.

Table 3. Experimental design: Actual (and encoded) levels of factors and observed responses.

\begin{tabular}{|c|c|c|c|}
\hline \multicolumn{3}{|c|}{ Factors } & \multirow[b]{2}{*}{$\mathrm{S}-\mathrm{SO}_{4}{ }^{2-}\left(\mathrm{mg} \mathrm{L}^{-1}\right)^{*}$} \\
\hline (1) Temperature $\left({ }^{\circ} \mathrm{C}\right)$ & (2) Time (min) & (3) $\mathrm{HCl}$ solution $(\%)$ & \\
\hline $150(-1)$ & $15(-1)$ & $12,5(-1)$ & 85.63 \\
\hline $170(+1)$ & $15(-1)$ & $12,5(-1)$ & 47.75 \\
\hline $150(-1)$ & $40(+1)$ & $12,5(-1)$ & 153.52 \\
\hline $170(+1)$ & $40(+1)$ & $12,5(-1)$ & 75.34 \\
\hline $150(-1)$ & $15(-1)$ & $25(+1)$ & 69.06 \\
\hline $170(+1)$ & $15(-1)$ & $25(+1)$ & 61.86 \\
\hline $150(-1)$ & $40(+1)$ & $25(+1)$ & 65.07 \\
\hline $170(+1)$ & $40(+1)$ & $25(+1)$ & 66.15 \\
\hline
\end{tabular}

*Mean values (triplicate)

A volume of 1 or $2 \mathrm{~mL}$ of $\mathrm{HCl}$ solution was added the in the optimization tests, representing, respectively, 12.5 and $25 \%$ of hydrochloric acid in the mixture for the extraction procedure. Table 4 shows the significance of the extraction process.

Table 4. Significance levels of parameters (effects) identified by analysis of variance (ANOVA).

\begin{tabular}{cccccccc}
\hline$\beta_{0}$ & $\beta_{1}$ & $\beta_{2}$ & $\beta_{3}$ & $\beta_{12}$ & $\beta_{13}$ & $\beta_{23}$ \\
\hline${\mathrm{S}-\mathrm{SO}_{4}{ }^{2-}}$ & & & & & & \\
\hline
\end{tabular}

$\beta_{0}$ (average of responses), $\beta_{1}$ (temperature), $\beta_{2}$ (time) e $\beta_{3}$ (HCl percentage). Bold numbers indicate significant factors as identified by the analysis of variance at the $95 \%$ confidence level. 
From the effects of the calculated parameters we have that factor $\beta_{2}$ (time) was the most significant (positive), i.e., the longer the extraction time, the better the yield. The other main effects (temperature and $\mathrm{HCl}$ percentage) presented low significance (negative), therefore, the extraction process is favored when these factors are at the lowest adjusted levels within the experimental planning $\left(150{ }^{\circ} \mathrm{C}\right.$ and $1 \mathrm{~mL}$, respectively). From the interaction of the evaluated factors, only the interaction $\beta_{13}$ (temperature and $\mathrm{HCl}$ percentage) was significant.

\subsubsection{Estimated Model}

A polynomial model was adjusted to the experimental data (Equation 2) with an $R^{2}=0.9871$ $\left(\mathrm{R}^{2}\right.$ adj $\left.=0.9811\right)$. The corresponding Analysis of Variance (ANOVA) data are shown in Table 5 .

$$
\hat{y}=78,05-15,26 x_{1}+11,98 x_{2}-12,50 x_{3}-4,01 x_{1} x_{2}+13,74 x_{1} x_{3}-11,91 x_{2} x_{3}
$$

Table 5. Analysis of variance (ANOVA) for the experimental results.

\begin{tabular}{cccccc}
\hline Source & Sum of square & $\begin{array}{c}\text { Degree of } \\
\text { freedom }\end{array}$ & Mean of square & $F$-value & P-value \\
\hline Model* & 9254.1744 & 3 & 3084.7248 & 6.8287 & 0.0061 \\
$\mathrm{X}_{1}$ & 3728.3236 & 1 & 3728.3236 & $\mathbf{4 . 7 6 8 3}$ & 0.0465 \\
$\mathrm{X}_{2}$ & 2296.8056 & 1 & 2296.8056 & 2.5977 & 0.1293 \\
$\mathrm{X}_{3}$ & 2502.5006 & 1 & 2502.5006 & 2.8782 & 0.1119 \\
$\mathrm{X}_{1} \mathrm{X}_{2}$ & 255.8400 & 1 & 255.8400 & 0.3657 & 0.5566 \\
$\mathrm{X}_{1} \mathrm{X}_{3}$ & 3023.3502 & 1 & 3023.35022 & $\mathbf{6 . 6 9 2 8}$ & 0.0238 \\
$\mathrm{X}_{2} \mathrm{X}_{3}$ & 2262.9049 & 1 & 2262.9049 & 3.5670 & 0.0833 \\
Error & 5420.7195 & 12 & 699.4937 & & \\
Cor. total & 14674.8943 & 15 & & & \\
& $\mathrm{R}^{2}=0.9871$ & $\mathrm{R}_{\text {adj. }}^{2}=0.98101$ & & & \\
\hline
\end{tabular}

$* \mathrm{X}_{1}=$ temperature, $\mathrm{X}_{2}=$ extraction time e $\mathrm{X}_{3}=$ hydrochloric acid percentage. Bold numbers indicate significant factors as identified by the analysis of variance at the $95 \%$ confidence level.

The analysis of variance (ANOVA) of organic sulphur extraction yield showed that experimental data had correlation coefficient $\left(\mathrm{R}^{2}\right)$ of 0.9871 . That means the calculated model could explain $98.71 \%$ of the results in the case of organic sulphur extraction yield. The results indicated that the model used to fit the response variable was significant $(\mathrm{P}<0.05)$ and adequate to represent the relationship between the response and the independent variables (Karabegovic et al., 2013; Zhao et al., 2011). For the linear effects of each independent variable within the experimental range, it can be seen in Table 4 that organic sulphur extraction yield was affected most significantly by temperature $\left(\mathrm{X}_{1}\right)(\mathrm{P}=0.0465)$, followed by hydrochloric acid percentage $\left(\mathrm{X}_{3}\right)(\mathrm{P}=0.1119)$ and extraction time $\left(\mathrm{X}_{2}\right)(\mathrm{P}=0.1293)$. For the interaction of factors, $\mathrm{X}_{1} \mathrm{X}_{3}$ (temperature $\times$ hydrochloric acid percentage) was the most significant. 


\section{$\Delta$ Macrothink}

\subsubsection{Response Surface Plot Analysis}

The graphical surface plots are very helpful when one wants to preview the effects of two factors on the response, as well as the identification path of steepest ascent for best response (Silva, Azevedo, Rezende, 2016). The effects of the independent variables and their mutual interaction on the extraction yield of organic sulphur can also be seen on three-dimensional response surface curves shown in Figures 1-3. The plots were generated by plotting the response using the z-axis against two independent variables while keeping the other two independent variables at their zero level.

Figure 1 shows the interaction between time and temperature in the extraction process. Based on the data, decreasing the temperature from $170{ }^{\circ} \mathrm{C}$ to $150{ }^{\circ} \mathrm{C}$ and the extraction time increasing from 15 to 40 minutes, best responses are achieved. The interaction between temperature and extraction time are critical factors in the extraction process, especially in pressurized containers. The increase of the temperature may have caused the volatilization of the solvents, which consequently resulted in loss in the extraction process.

Figure 2 shows the interaction between percentage of $\mathrm{HCl}$ solution with the extraction temperature. Decreasing the temperature from $170{ }^{\circ} \mathrm{C}$ to $150{ }^{\circ} \mathrm{C}$ and decreasing the percentage of $\mathrm{HCl}$ solution from 25 to $12.5 \%$ in acid mixture, the extraction process is improved. The turbidimetric determination is directly linked to the percentage of hydrochloric acid in the mixture of acids. So, as already discussed, the lower volume of $\mathrm{HCl}$ solution used in the solvent mixture provides a clear filtrate and consequently a better spectrophotometric response.

Figure 3 indicates that the path of the best response is at a longer extraction time (40 min), using the lower percentage of hydrochloric acid for extraction, i.e., the ratio 7:1 (by volume) of nitric and hydrochloric acids, respectively.

$\mathrm{HCl}(12.5 \%)$

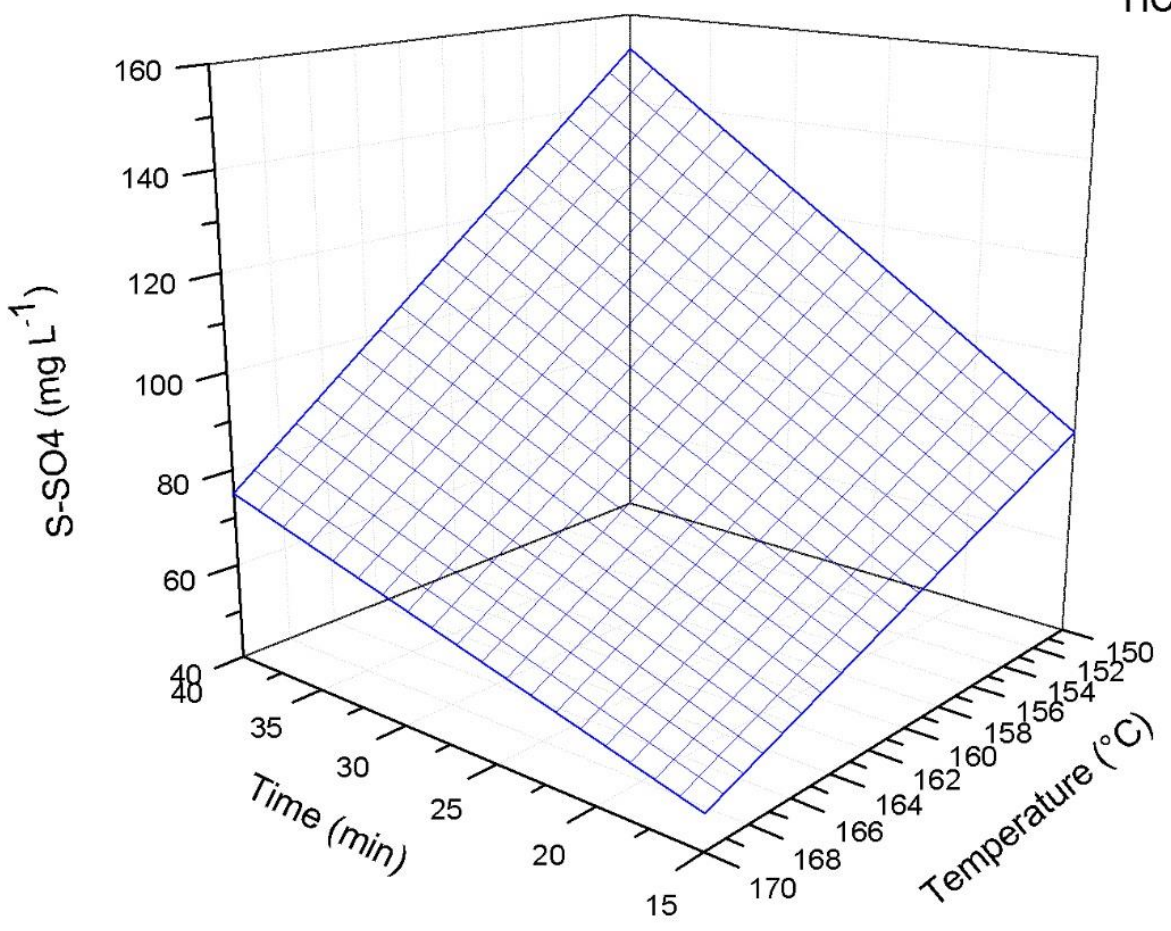

Figure 1. Graphical surface plot. Time x Temperature. 


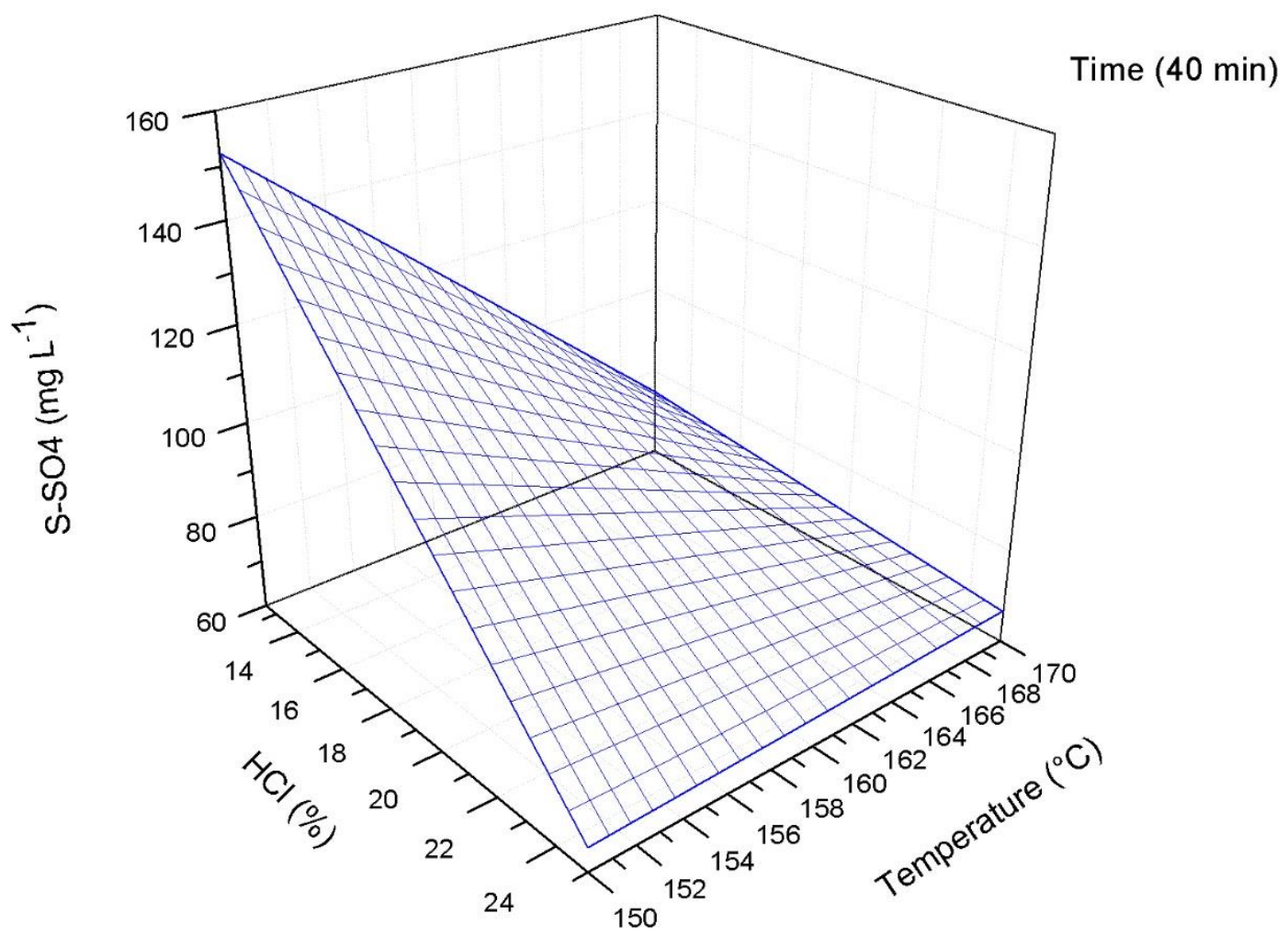

Figure 2. Graphical surface plot. $\mathrm{HCl}$ solution percentage x Temperature.

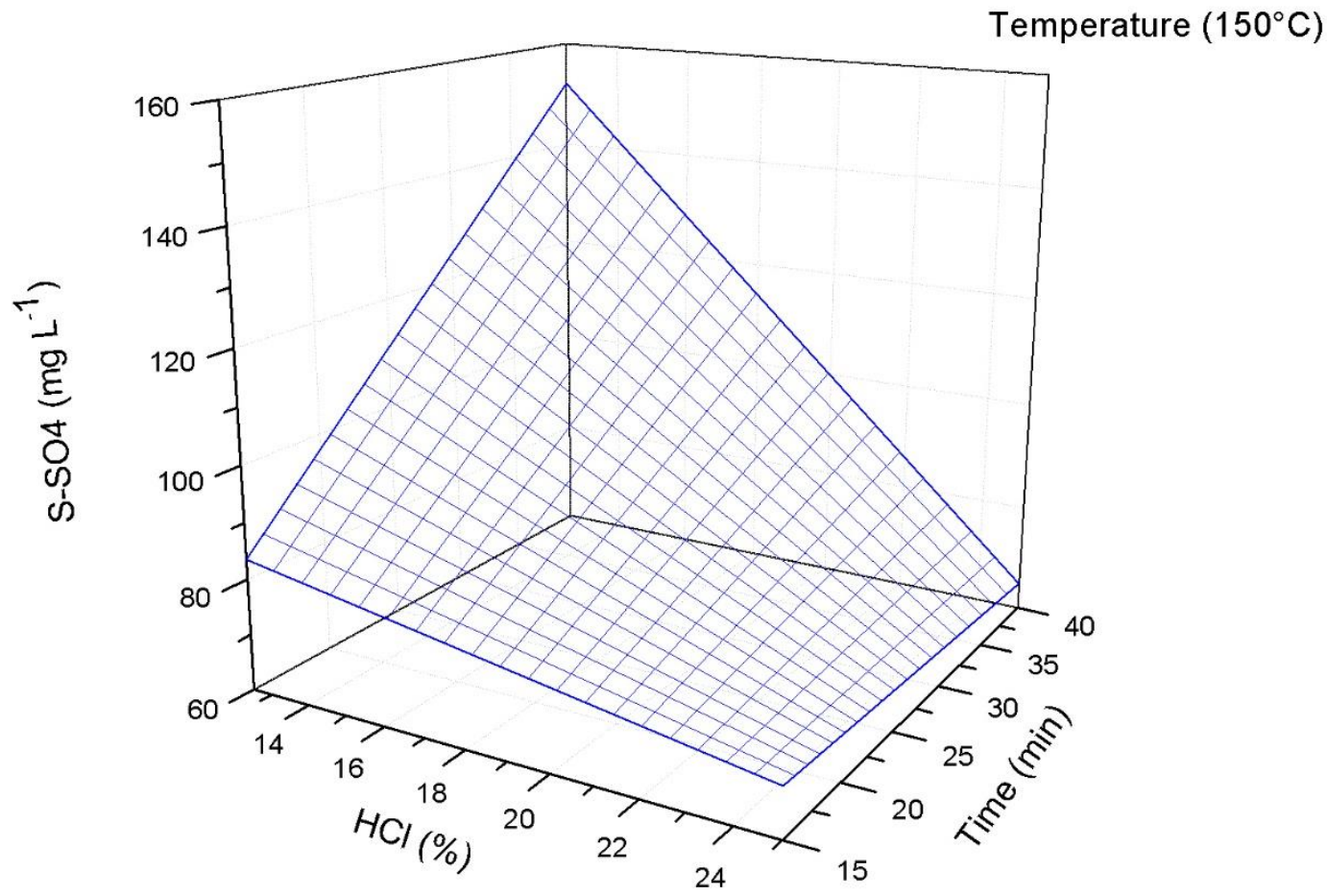

Figure 3. Graphical surface plot. $\mathrm{HCl}$ solution percentage x Time. 


\subsection{Recovery Assay: Yield of Extraction}

After method optimization, the extraction of organic sulphur in sewage sludge was done under optimized operational conditions, i.e., temperature: $150{ }^{\circ} \mathrm{C}$, pressure: 35 bars, ramp time: 8 minutes, extraction time: 40 minutes and magnetron power output of the microwave unit at $90 \%$, using $0.5 \mathrm{~g}$ of sewage sludge, plus the mixture of $\mathrm{HNO}_{3}(7 \mathrm{~mL})$ and $\mathrm{HCl}(1$ $\mathrm{mL})$.

The analytical curve containing $10,25,50,75,100$ and $200 \mathrm{mg} \mathrm{L}^{-1}$ of $\mathrm{S}_{-} \mathrm{SO}_{4}{ }^{2-}$ presented a linear regression of 0.99 , evidencing the linearity of the quantification method. With the satisfactory results regarding the optimization tests, samples of sewage sludge were prepared and the accuracy of the method was evaluated. The spiked samples were carried out at three fortification levels, 25,50 and $100 \mathrm{mg}$. $\mathrm{L}^{-1}$. The sulfur data recoveries in sewage sludge samples are presented in the Table 6.

Table 6. Average recoveries of organic sulphur in sewage sludge sample.

\begin{tabular}{cccc}
\hline & Added $\left(\mathrm{mg} \mathrm{L}^{-1}\right)$ & & \\
\cline { 3 - 4 } & & $\begin{array}{c}\text { Recovery } \\
(\%)\end{array}$ & $\begin{array}{c}\text { RSD } \\
(\mathrm{n}=3)\end{array}$ \\
\hline \multirow{2}{*}{ Sample } & 25 & 86.2 & 4.17 \\
& 50 & 97.5 & 10.52 \\
& 100 & 111.2 & 13.12
\end{tabular}

Recoveries are between $86.2 \%$ and $111.2 \%$, so the accuracy is acceptable. Based on the initially adjusted parameters (time, temperature, and volume of hydrochloric acid solution), the proposed methodology meets the initial objective, since the digestion times commonly used in methodologies of extraction of metals and/or nitrogen in several matrices consume on average 1 hour. The organic sulphur $\left(\mathrm{S}_{-} \mathrm{SO}_{4}{ }^{2-}\right)$ content in the sewage sludge samples evaluated were around $6.34 \mathrm{mg} \mathrm{L}^{-1}$.

In general, conventional extraction techniques that use strong acids, are time consuming and some analytical methodologies are potentially susceptible to contamination and loss of chemical elements by volatilization. In other methods, which use the oven, samples may be burnt, causing some chemical elements to be lost by volatilization or adsorbed on the furnace wall. MAE digestion presents advantages, because it reduces the preparation time of sample, it uses minor sample mass and solvent volume, as well as the risks associated to classical methods, mainly, contamination and loss of volatile chemical elements.

\section{Conclusion}

Statistical analysis indicated that the optimum MAE conditions for the determination of sulfur in sludge samples were the mixture of $\mathrm{HNO}_{3}(7 \mathrm{~mL})$ and $\mathrm{HCl}(1 \mathrm{~mL})$ concentrated with an extraction time of 40 minutes at $150{ }^{\circ} \mathrm{C}$. The extraction procedure is fast, considering the sample mass used $(0.5 \mathrm{~g})$ and the time of the preparation of the sample that is minimized.

This study has demonstrated the feasibility of the use microwave radiation in the extraction of organic sulphur in soil sample. Design of experiment provides an efficient working strategy to explore conditions which ensure the optimum responses. 
The digestion method used for further turbidimetric determination requires some caution, especially with the final filtrate, extracts of dark or yellowish coloration are not suitable for determination by turbidimetry. In general, the optimized MAE method provided good recovery rates.

\section{Acknowledgement}

The authors would like to acknowledge FAPEMA (Maranhão Foundation for the Protection of Research and Scientific and Technological Development), CNPq (National Council for Scientific and Technological Development) process number 306715/2013-9, FAPESP (São Paulo Research Foundation) process number 2013/13093-7 and NAP 2012-CiTecBio, Provost for Research, University of São Paulo.

\section{References}

Barriada -Pereira, M.; Concha-Grana, E.; González-Castro, M. J.; Muniategui-Lorenzo, S.; López-Mahía, P.; Prada-Rodríguez, D.; Fernández-Fernández, E. (2003). Microwave-assisted extraction versus Soxhlet extraction in the analysis of 21 organochlorine pesticides in plants. Journal of Chromatography A, 1008, 115-122.

http://dx.doi.org/10.1016 /S0021-9673(03)01061-6

Du, G.; Zhao, H. Y.; Zhang, Q. W.; Li, G. H.; Yang, F. Q.; Wang, Y.; Li, Y. C.; Wang, Y. T. (2010). A rapid method for simultaneous determination of 14 phenolic compounds in Radix Puerarie using microwave-assisted extraction and ultra high performance liquid chromatography coupled with diode array detection and time-of-flight mass spectrometry. Journal of Chromatography A, 1217, 705-714.

http://dx.doi.org/ 10.1016/j.chroma.2009.12.017

Gomes, S. B. V.; Nascimento, C. W. A.; Biondi, C. M. (2007). Produtividade e composição mineral de planta de milho em solo adubado com lodo de esgoto. Revista Brasileira de Engenharia Agrícola e Ambiental, 11(5), 459-465, 2007.

Heck, K.; De Marco, E. G.; Hahn, A. B. B.; Kluge, M.; Spilki, F. R.; Van Der Sand, S. T. (2013). Temperatura de degradação de resíduos em processo de compostagem e qualidade microbiológica do composto final. Revista Brasileira de Engenharia Agrícola e Ambiental, 17 (1), 54-59.

Huang, Y-F.; Shih, C-H.; Chiueh, P-T.; Lo, S-L. (2015). Microwave co-pyrolisis of sewage sludge and rice straw. Energy, 87, 638-644. https://doi.org/10.1016/j.energy.2015.05.039

Karabegovic, I. T.; Stojicevic, S. S.; Velickovic, D. T.; Nikolic, N. C.; Lazic, M. L. (2013). Optimization of microwave-assisted extraction and characterization of phenolic compounds in cherry laurel (Prunus laurocerasus) leaves. Separation and Purification Technology, 120, 429-436. https://doi.org/10.1016/j.seppur.2013.10.021

Khan, A. H.; Shang, J. Q.; Alam, R. (2012). Ultrasound-assisted extraction for total sulphur measurement in mine tailing. Journal of Hazardous Materials, 235, 376-383. https://doi.org/10.1016/j.jhazmat.2012.08.018 
Li, H.; Deng, Z.; Wu, T.; Liu, R.; Loewen, S.; Tsao, R. (2012). Microwave-assisted extraction of phenolics with maximal antioxidant activities in tomatoes. Food Chemistry, 130, 928-936. https://doi.org/10.1016/j.foodchem.2011.08.019

Lucheta, A. R.; Lambais, M. R. (2012). Sulphur in agriculture. Revista Brasileira de Ciência do solo, 36, 1369-1379. http://dx.doi.org/10.1590/S0100-06832012000500001

Rossete, A. L. R. M.; Carneiro, J. M. T.; Bategello, H. H.; Oliveira, J. G. G.; Bendassolli, J. A. (2011). Determinação de enxofre em amostras vegetais por oxidação via seca em meio alcalino com detecção espectrofotométrica. Química Nova, 34 (2), 341-343.

Rossete, A. L. R. M.; Carneiro, J. M. T.; Sant Ana Filho, R.; Bendassolli, J. A. (2012). Isotope determination of sulphur by mass spectrometry in soil samples. Revista Brasileira de Ciência do solo, 36, 1787-1793. http://dx.doi.org/10.1590/S0100-06832012000600012

Rossete, A. L. R. M.; Carneiro, J. M. T.; Bendassolli, J. A.; Trivelin, P. C. O. (2008). Organic sulphur oxidation to sulfate in soil for total sulphur determination by turbidimetry. Revista Brasileira de Ciência do solo, 32 (6), 2547-2553.

http://dx.doi.org/10.1590/S0100-06832008000600031

Silva, D. F.; Landgraf, M. D. and Rezende, M. O. (2015). Fast and sustainable determination of persistent organic pollutants from organic fertilizer using microwave-assisted extraction method and gas chromatography-mass spectrometry. Open Access Library Journal, 2, 1-8. http://dx.doi.org/10.4236/oalib.1102049

Silva, D. F.; Azevedo, E. B.; Rezende, M. O. O. (2016). Optimization of microwave-assisted extraction of a bioherbicide from Canavalia ensiformis leaves. American Journal of Environmental Sciences, 12 (1), 27-32. http://dx.doi.org/10.3844/ajessp.2016.27.32

Silva, D. F.; Landgraf, M. D. and Rezende, M. O. (2017). Assessment of triazines herbicides in soil by microwave-assisted extraction followed by gas chromatography coupled to mass spectrometry detection. Journal of Chemistry and Chemical Engineering, 11, 1-8.

http://dx.doi.org/10.17265/1934-7375/2017.01.001

Tabatabai, M. A. (1974). A rapid method for determination of sulfate in water sample. Environmental Letters, 7 (3), 237-243.

Vicente, S.; Borges, E. P.; Reis, B. F.; Zagatto, E.A.G. (2001). Exploitation of tandem stream for carry-over compensation in flow analysis I. Turbidimetric determination of potassium in fertilizers. Analytica Chimica Acta, 438, 3-9. https://doi.org/10.1016/S0003-2670(00)01305-2

Zhao, W.; Yu, Z.; Liu, J.; Yu, Y.; Yin, Y.; Lin, S.; Chen, F. (2011). Optimized extraction of polysaccharides from corn silk by pulsed electric field and response surface quadratic design. Journal of the Science of Food and Agriculture, 91, 2201-2209.

http://dx.doi.org/10.1002/jsfa.4440 


\section{Copyright Disclaimer}

Copyright for this article is retained by the author(s), with first publication rights granted to the journal.

This is an open-access article distributed under the terms and conditions of the Creative Commons Attribution license (http://creativecommons.org/licenses/by/4.0/). 